\title{
Antibacterial Activity of Pluchea indica and Piper betle Ethanol Extract on Staphylococcus epidermidis and Pseudomonas aeruginosa
}

\author{
Nela $^{1}$, Umi Yuniarni ${ }^{1}$, Diki Prayugo ${ }^{2}$ \\ ${ }^{1}$ Department of Pharmacology, Sekolah Tinggi Farmasi Indonesia, Bandung, West Java, Indonesia \\ ${ }^{2}$ Department of Biology Pharmacy, Sekolah Tinggi Farmasi Indonesia, Bandung, West Java, Indonesia
}

\begin{abstract}
Medicinal plants are widely used for the treatment of different infectious diseases. This study was aimed to investigate antibacterial activity of Pluchea indica (P. indica) and Piper betle (P.betle) ethanol extract on Staphylococcus epidermidis (S. epidermidis) and Pseudomonas aeruginosa (P. aeruginosa) using agar disk diffusion method. Ethanol extract of Piper betle showed more potent antibacterial activity than $P$. indica against $S$. Epidermidis with the highest inhibiton zone at $30.71 \mathrm{~mm}$ and $21.73 \mathrm{~mm}$ from $1 \mathrm{mg} / \mathrm{ml}$ concentration, respectively. In contrast, against $P$. aeruginosa, the ethanol extract of $P$. indica was more potent than $P$. betle with $21.44 \mathrm{~mm}$ and $20.12 \mathrm{~mm}$ of inhibition zone on $1 \mathrm{mg} / \mathrm{ml}$ concentration, respectively. There was no increased effect from the combination of these two extracts against these bacteria. When comparing the antibacterial activity of these extract with tetracycline as the standard, we found that antibacterial activity of $P$. indica at the concentration of $0.9 \mathrm{mg} /$ $\mathrm{ml}$ was comparable with that of tetracycline at concentration of $12.52 \mu \mathrm{g} / \mathrm{ml}$, while $P$. betle needed $0.3 \mathrm{mg} / \mathrm{ml}$ concentration to had similar activity with $10.51 \mu \mathrm{g} / \mathrm{ml}$ of tetracycline. In conlusion, the antibacterial activity of ethanol extracts of $P$. indica and $P$. betle indicated that these extract had sufficient potential to warrant further examination and development as a new antibacterial agent.
\end{abstract}

Keywords: Pluchea indica, Piper betle, antibacterial, agar disk diffusion

\section{Introduction}

Inappropriate use of antimicrobial drugs contributes to the emergence and spread of drug resistant. This situation has encouraged the development of new antimicrobial substances from various sources, such as medicinal plants. ${ }^{1-3}$ Medicinal plants are widely used empirically for the treatment of infectious disease. Investigation of safety and efficacy of these plants as the candidate of potential antimicrobial agent is considered necessary. $^{4,5}$

Indonesia has enormous variety of medicinal plants, including Piper betle (P. betle) and Pluchea indica (P. indica). P. betle is usually used for the treatment of mouth ulcers, hemorrhoids, stomach disorders, etc. $P$. indica is known as body deodorizing agent. It is usually consumed as fresh vegetables, decoction, and topical medication. ${ }^{6-10}$

Corresponding author: Nela. Department of Pharmacology, Sekolah Tinggi Farmasi Indonesia, West Java, Indonesia. Email: nelasimanjuntak89@gmail.com 
Staphylococcus epidermidis (S. epidermidis) and Pseudomonas aeruginosa (P. aeruginosa) are two most prevalent bacterial pathogens infecting respiratory disease, urinary tract, eyes, and burn wounds. Their presence was associated with poor patient outcomes. ${ }^{11,12}$

Previous studies showed that $P$. indica extract could inhibit the growth of several gram-positive bacteria, including $B$. cereus, $B$. subtilis, and $S$. aureus. $P$. betle also had potential antibacterial activity against $S$. aureus, E. coli, S. typhi, and S. dysenteriae..$^{13,14}$ However, there is a lack of study investigating antibacterial activity of these extracts against $S$. epidermidis and P. aeruginosa. Therefore, we conducted this study to investigate antibacterial activity of ethanol extract of $P$. indica and $P$. betle against $S$. epidermidis and $P$. aeruginosa.

\section{Methods}

\section{Materials and instruments}

The materials used in this study included $P$. betle leaves, $P$. indica leaves, $S$. epidermidis and $P$. aeruginosa. For phytochemical screening, the reagent of Mayer, Dragendorff, Liebermann-Burchard, ether, amyl alcohol, $\mathrm{HCl} 2 \mathrm{~N}, 5 \% \mathrm{KOH}, \mathrm{FeCl}_{3}$, vanillin $10 \%$ in concentrated $\mathrm{H}_{2} \mathrm{SO}_{4}, 1 \%$ gelatine, ammonia, magnesium powders and distilled water were used. Extraction was performed using
95\% ethanol solvent (Brataco). Antibacterial activity test was conducted using growth media of agar nutrient (Deffco), broth nutrient (Deffco), physiological $\mathrm{NaCl}$ (Otsuka), ethanol 70\% (Brataco), disinfectant, and distilled water. Tools used in this study included soxhlet extractor, rotary evaporator, and laboratory glass tools.

\section{Antibacterial activity test procedure}

All materials and instruments, including agar nutrient and distilled water were sterilized using an autoclave at $121{ }^{\circ} \mathrm{C}$ for 15 minutes. It was dried in the oven for 15 minutes. The bacteria colonies were rejuvenated and incubated at $37^{\circ} \mathrm{C}$ for $18-24$ hours. The colonies were then put in a sterilized physiological $\mathrm{NaCl}$ solution. It was measured at spectrophotometer with $\lambda=580 \mathrm{~nm}$ to obtain $\mathrm{T}=25 \%$.

Agar nutrient solution was obtained by dissolving it with distilled water and stirring it on water bath until a clear solution was obtained. $20 \mathrm{ml}$ sterilized agar nutrient solution was put into petri dishes. $50 \mu \mathrm{l}$ bacterial suspension was added into petri dish. It was then homogenized until hardened agar formed. Using perforator, a hole was formed on each agar with a diameter of 10 mm. $50 \mu \mathrm{l}$ of various concentration of $P$. indica and $P$. betle extracts were put in each

Table 1. Phytochemical screening of $P$. betle

\begin{tabular}{lccc}
\hline \multicolumn{1}{c}{ Secondary Metabolite } & Crude materials & Ethanol Extract & MMI \\
\hline Alkaloid & + & + & + \\
Flavonoid & + & + & + \\
Tannin & + & + & + \\
Phenolic acid & + & + & + \\
Monoterpene dan Sesquiterpene & + & + & + \\
Steroid dan Triterpenoid & - & - & - \\
Quinone & + & + & + \\
Saponin & - & - & - \\
& - & - & - \\
\hline
\end{tabular}


Table 2. Phytochemical screening of $P$. indica

\begin{tabular}{lccc}
\hline \multicolumn{1}{c}{ Secondary Metabolite } & Crude materials & Ethanol Extract & MMI \\
\hline Alkaloid & + & + & + \\
Flavonoid & + & + & + \\
Tannin & + & + & + \\
Phenolic acid & + & + & + \\
Monoterpene dan Sesquiterpene & + & + & - \\
Steroid dan Triterpenoid & - & + & + \\
Quinone & + & + & + \\
Saponin & + & - & - \\
\end{tabular}

agar nutrient $(0.2 \mathrm{mg} / \mathrm{ml} ; 0.4 \mathrm{mg} / \mathrm{ml} ; 0.6 \mathrm{mg} /$ $\mathrm{ml} ; 0.8 \mathrm{mg} / \mathrm{ml} ; 1 \mathrm{mg} / \mathrm{ml})$.

Each petri dish was incubated at $37{ }^{\circ} \mathrm{C}$ for 18-24 hours. After incubation, the clear zone formed around the hole was measured in diameter by using a vernier caliper. The concentrations which gave inhibiton zone more than $20 \mathrm{~mm}$ in the first experiment were selected and combined. The similar antibacterial testing was then performed for these combination.

Antibacterial activity compared to tetracycline

Comparation of antibacterial activity between these extracts and tetracycline aimed to understand the extent to which antibacterial

Table 3. Antibacterial activity of $P$. indica and $P$. betle against $S$. epidermidis and $P$. aeruginosa

\begin{tabular}{|c|c|c|c|c|c|c|c|}
\hline \multirow[b]{2}{*}{ Extract } & \multirow[b]{2}{*}{ Bacteria } & \multicolumn{6}{|c|}{ Inhibition Zone (mm) } \\
\hline & & Control & $\begin{array}{c}0.2 \\
\mathrm{mg} / \mathrm{ml}\end{array}$ & $\begin{array}{c}0.4 \\
\mathrm{mg} / \mathrm{ml}\end{array}$ & $\begin{array}{c}0.6 \\
\mathrm{mg} / \mathrm{ml}\end{array}$ & $\begin{array}{c}0.8 \\
\mathrm{mg} / \mathrm{ml}\end{array}$ & $\begin{array}{c}1 \\
\mathrm{mg} / \mathrm{ml}\end{array}$ \\
\hline \multirow{8}{*}{ P. indica } & S. epidermidis & 9 & 10.11 & 14.71 & 16.56 & 19.16 & 21.57 \\
\hline & & 9 & 10.49 & 14.61 & 16.85 & 19.57 & 21.87 \\
\hline & & 9 & 10.38 & 14.81 & 16.34 & 18.98 & 21.75 \\
\hline & Mean & 9 & 10.32 & 14.71 & 16.58 & 19.23 & 21.73 \\
\hline & P. aeruginosa & 9 & 9.78 & 10.78 & 12.61 & 14.56 & 21.60 \\
\hline & & 9 & 9.87 & 10.87 & 12.37 & 14.78 & 21.17 \\
\hline & & 9 & 9.88 & 10.97 & 12.35 & 14.91 & 21.55 \\
\hline & Mean & 9 & 9.84 & 10.87 & 12.44 & 14.75 & 21.44 \\
\hline \multirow{8}{*}{ P. betle } & S. epidermidis & 9 & 16.71 & 22.61 & 24.55 & 27.17 & 30.57 \\
\hline & & 9 & 16.87 & 21.83 & 24.81 & 27.56 & 30.72 \\
\hline & & 9 & 16.75 & 21.32 & 24.33 & 27.81 & 30.81 \\
\hline & Mean & 9 & 16.77 & 21.92 & 24.56 & 27.51 & 30.71 \\
\hline & P. aeruginosa & 9 & 11.65 & 13.81 & 15.71 & 17.12 & 20.13 \\
\hline & & 9 & 11.87 & 13.12 & 15.68 & 17.87 & 19.74 \\
\hline & & 9 & 11.98 & 13.51 & 15.19 & 17.41 & 20.51 \\
\hline & Mean & 9 & 11.83 & 13.51 & 15.52 & 17.46 & 20.12 \\
\hline
\end{tabular}

diameter of perforator: $9 \mathrm{~mm}$ 
Table 4. Antibacterial activity of combination of $P$. indica and $P$. betle against $S$. epidermidis and $P$. aeruginosa

\begin{tabular}{|c|c|c|c|c|c|}
\hline \multirow{2}{*}{ Extract } & \multirow{2}{*}{ Bacteria } & \multicolumn{4}{|c|}{ Inhibition Zone (mm) } \\
\hline & & Control & 1 & 2 & 3 \\
\hline \multirow{8}{*}{ P. indica } & S. epidermidis & 9 & 20.12 & 19.85 & 20.36 \\
\hline & & 9 & 20.91 & 20.15 & 20.39 \\
\hline & & 9 & 19.87 & 19.78 & 19.97 \\
\hline & Mean & 9 & 20.11 & 20.48 & 19.87 \\
\hline & P. aeruginosa & 9 & 18.78 & 17.85 & 18.36 \\
\hline & & 9 & 18.67 & 18.15 & 18.39 \\
\hline & & 9 & 17.99 & 18.78 & 18.97 \\
\hline & Mean & 9 & 18.48 & 18.26 & 18.57 \\
\hline \multirow{8}{*}{ P. betle } & S. epidermidis & 9 & 21.52 & 20.85 & 21.87 \\
\hline & & 9 & 22.51 & 21.52 & 20.81 \\
\hline & & 9 & 19.78 & 21.81 & 20.11 \\
\hline & Mean & 9 & 21.41 & 21.61 & 20.56 \\
\hline & P. aeruginosa & 9 & 22.52 & 22.85 & 22.87 \\
\hline & & 9 & 22.51 & 21.52 & 22.81 \\
\hline & & 9 & 22.78 & 21.81 & 22.11 \\
\hline & Mean & 9 & 22.60 & 22.04 & 22.59 \\
\hline
\end{tabular}

activity of the extract was similar with that of standard treatment. The score was obtained by comparing inhibition zone of the extract and the standard. The result of comparative observation was then illustrated in a curve with concentration $\log$ data on $\mathrm{x}$-axis and inhibiton zone diameter $(\mathrm{mm})$ on y-axis. This curve was used to compare the substance which had the highest antibacterial activity.

\section{Results and Discussion}

Phytochemical screening result showed that both extracts contained alkaloids, flavonoids, tannins, phenolics, monoterpenes, steroids, triterpenoids and quinones (Table 1 and 2). Table 3 shows the result of antibacterial activity from $P$. indica and $P$. betle leaves ethanol extract against $S$. epidermidis and $P$. aeruginosa bacteria. We found that mean inhibiton zone diameter of $P$. indica extract against $S$. epidermidis was $21.73 \mathrm{~mm}$ at $1 \mathrm{mg} /$ $\mathrm{ml}$ concentration and against $P$. aeruginosa was $21.44 \mathrm{~mm}$ with the same concentration. $P$. betle could produce inhibitory zone with diameter of $21.92 \mathrm{~mm}$ at concentration 0.4 $\mathrm{mg} / \mathrm{ml}$ against $S$. epidermidis, while against $P$. aeruginosa, it gave $20.12 \mathrm{~mm}$ inhibitory zone with the same concentration. Table 4 shows the inhibitory zone of combination of these extracts. There was a difference in inhibitory diameter for both bacteria. For $S$. epidermidis, combination $1(0.15 \mathrm{mg} /$ $\mathrm{ml} P$. betle and $0.45 \mathrm{mg} / \mathrm{ml} P$. indica) gave a mean inhibitory diameter of $20.15 \mathrm{~mm}$, while against $P$. aeruginosa it could produce a mean inhibitory diameter of $18.43 \mathrm{~mm}$. Combination 2 gave inhibitory diameter of $21.19 \mathrm{~mm}$ and $22.41 \mathrm{~mm}$, against $S$. epidermidis and $P$. aeruginosa respectively. There was no increased effect of antibacterial acitivity of combined extract of $P$. indica and P. betle.

Various concentration of tetracycline were 
Table 5. Antibacterial activity of tetracycline

\begin{tabular}{lccccccc}
\hline & & \multicolumn{5}{c}{ Inhibition Zone (mm) } \\
\cline { 2 - 8 } & Bacteria & Control & $\mathbf{1 0}$ & $\mathbf{7 . 5}$ & $\mathbf{5}$ & $\mathbf{2 . 5}$ & $\mathbf{1 . 2 5}$ \\
\cline { 2 - 8 } & 1 & 9 & 21.87 & 20.54 & 19.72 & 18.11 & 17.65 \\
& 2 & 9 & 21.81 & 20.59 & 19.71 & 18.21 & 17.59 \\
& 3 & 9 & 21.78 & 20.45 & 19.68 & 18.12 & 17.55 \\
Mean & & $\mathbf{9}$ & 21.82 & 20.52 & 19.70 & 18.17 & 17.59 \\
\hline S. epidermidis & 1 & 9 & 23.64 & 22.78 & 21.38 & 20.48 & 19.16 \\
& 2 & 9 & 23.72 & 22.68 & 21.42 & 20.52 & 19.24 \\
Mean & 3 & 9 & 23.66 & 22.74 & 21.42 & 20.60 & 19.14 \\
diameter of perforator: $9 \mathrm{~mm}$ & & $\mathbf{9}$ & 23.67 & 22.73 & 21.41 & 20.53 & 19.18 \\
\hline
\end{tabular}

tested for their antibacterial activity against $S$. epidermidis and $P$. aeruginosa using the agar diffusion method. The results of the test can be seen in Table 5. The result of tetracycline standard curve with log concentration data on $\mathrm{x}$-axis and inhibitory diameter $(\mathrm{mm})$ on $\mathrm{y}$-axis was illustrated in figure 1. Based on linear regression equation with $y=4.558$ $x+16.76 \mathrm{R}^{2}=0,942$ in Figure 1 , for $P$. aeruginosa bacteria, activity produced by $P$. indica at concentration of $1 \mathrm{mg} / \mathrm{ml}$ was comparable with that of tetracycline at the concentration of $9.89 \mu \mathrm{g} / \mathrm{ml}$. The antibacterial activity produced by $P$. betle at the concentration of $1 \mathrm{mg} / \mathrm{ml}$ was comparable with that of tetracycline at $11.49 \mu \mathrm{g} / \mathrm{ml}$. The combination $1(0.3 \mathrm{mg} / \mathrm{ml} \mathrm{P}$. betle and 0.45 $\mathrm{mg} / \mathrm{ml} P$. indica) was comparable to $14 \mu \mathrm{g} /$ $\mathrm{ml}$ tetracycline while combination $2(0.5$ $\mathrm{mg} / \mathrm{ml}$ P. betle and $0.5 \mathrm{mg} / \mathrm{ml} P$. indica) was equivalent to $10 \mu \mathrm{g} / \mathrm{ml}$ (Figure 1).

Based on linear regeression equation with $y=$ $4,554 x+17,84$ with $\mathrm{R}^{2}=0.940$ in Figure 2 , for S. epidermidis bacteria, antibacterial activity of $P$. indica at concentration of $0.9 \mathrm{mg} / \mathrm{ml}$ was comparable with that of tetracycline at $12.52 \mu \mathrm{g} / \mathrm{ml}$, and the antibacterial activity produced by $P$. betle at $0.3 \mathrm{mg} / \mathrm{ml}$ was comparable with $10.51 \mu \mathrm{g} / \mathrm{ml}$ tetracycline.

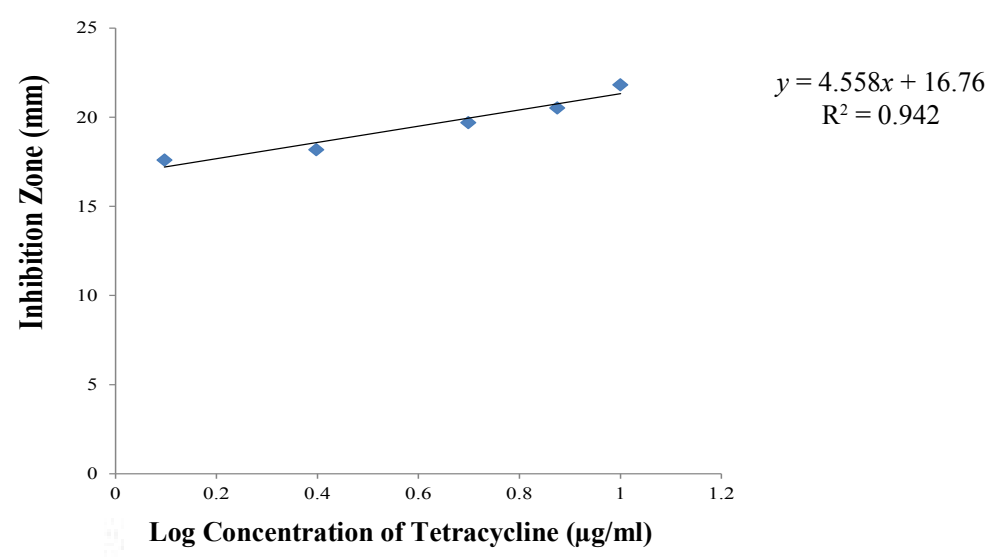

Figure 1. Standard curve of tetracycline antibacterial activity against $P$. aeruginosa 


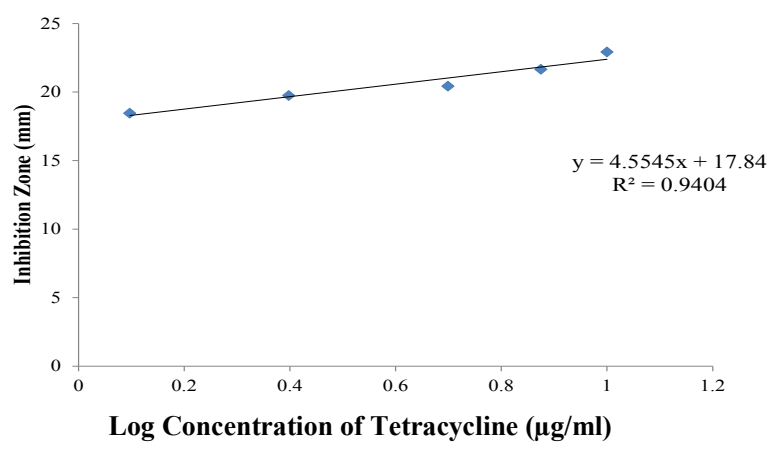

Figure 2. Standard curve of tetracycline antibacterial activity against $S$. epidermidis

The activity produced by combination 1 was comparable with $12.92 \mu \mathrm{g} / \mathrm{ml}$ tetracycline and combination 2 was equivalent to the activity of tetracycline at the concentration of $9.98 \mu \mathrm{g} / \mathrm{ml}$.

Our finding was comparable with previous studies. ${ }^{14,15}$ Bioactive compounds which might contribute in the antibacterial activity of these plants were dependent on solvent system. Previous study showed that organic solvent could retain more antibacterial compunds compared to water solvent. Since our study used ethanol solvent for extraction, the result was comparable. Several studies reported that terpenoid, flavonoid, alkaloid, and tannin were responsible for the antibacterial acitivity. ${ }^{16}$

\section{Conclusion}

The ethanol extract of $P$. betle showed more potent antibacterial activity against $S$. epidermidis compared to $P$. indica, while against $P$. aeruginosa, $P$. indica was more potent than $P$. betle. There was no increased effect from the combination of these extracts against two bacteria. $P$. indica and $P$. betle had sufficient potential to warrant further examination and development as a new antibacterial agent. Further research might be needed to identify and isolate bioactive substances which contribute in antibacterial activity from these plants.

\section{References}

1. Ventola CL. The antibiotic resistance crisis: causes and threats. Pharmacy and Therapeutics. 2015;40(4):277-283.

2. Llor C, Bjerrum L. Antimicrobial resistance: risk associated with antibiotic overuse and initiatives to reduce the problem. Therapeutic Advances in Drug Safety. 2014;5(6):229-241.

3. Fair RJ, Tor Y. Antibiotics and bacterial resistance in the $21^{\text {st }}$ century. Perspectives in Medicinal Chemistry. 2014;6:25-64.

4. Ekor M. The growing use of herbal medicines: issues relating to adverse reactions and challenges in monitoring safety. Frontiers in Pharmacology. 2013;4:177.

5. Leonti M, Casu L. Traditional medicines and globalization: current and future perspectives in ethnopharmacology. Frontiers in Pharmacology. 2013;4:92.

6. Wan Harun A, Jamil NA, Jamaludin NH, Nordin MAF. Effect of Piper betle and Brucea javanica on the differential expression of hyphal wall protein (HWP1) in non-candida albicans species. Evidence-based Complementary and Alternative Medicine. 2013;39:726.

7. Vu TT, Kim H, Tran VK. In vitro antibacterial activity of selected medicinal 
plants traditionally used in Vietnam against human pathogenic bacteria. BMC Complementary and Alternative Medicine. 2016;16:32.

8. Arsiningtyas IS, Gunawan MD, Kato E, Kawabata J. Identification of $\alpha$-glucosidase inhibitors from the leaves of Pluchea indica (L.) Less, a traditional Indonesian herb:promotion of natural product use. Natural Products Research. 2014;28:1350-1353.

9. Buapool D, Mongkol N, Chantimal J, Roytrakul S. Molecular mechanism of anti-inflammatory activity of Pluchea indica leaves in macrophages RAW 264 and its action in animal models of inflammation. Journal of Ethnopharmacology. 2013;146:495-504.

10. Kao CL, Cho J, Lee YZ, Cheng YB, Chien CY. Ethanolic extracts of Pluchea indica induce apoptosis and antiproliferation effects in human nasopharyngeal carcinoma cells. Molecules. 2015;20:11508-11523.

11. Fodor AA, Klem ER, Gilpin DF, Elborn JS, Boucher RC, Tunney MM. The adult cystic fibrosis airway microbiota is stable over time and infection type, and highly resilient to antibiotic treatment of exacerbations. PLoS One. 2012;7:450.
12. Datta S, Jana D, Maity TR, Samanta A, Banerjee R. Piper betle leaf extract affects the quorum sensing and hence virulence of Pseudomonas aeruginosa. Biotechnology. 2016;6(1):18.

13. Nair R, Chanda S. Antimicrobial Activity of Terminalia catappa, Manilkara zapota and Piper betle leaf extract. Indian Journal of Pharmaceutical Sciences. 2008;70(3):390-393.

14. Rahman MA, Islam MS. Antioxidant, antibacterial and cytotoxic effects of the phytochemicals of whole Leucas aspera extract. Asian Pacific Journal of Tropical Biomedicine. 2013;3:273-279.

15. Akter KN, Karmakar P, Das A, Anonna SN, Shoma SA. Evaluation of antibacterial and anthelmintic activities with total phenolic contents of Piper betle leaves. Avicenna Journal of Phytomedicine. 2014;4(5):320-329.

16. Sule WF, Okonko IO, Omo-Ogun S, Nwanze JC, Ojezele MO. Phytochemical properties and in vitro antifungal activity of Senna alata Linn crude stem bark extract. Journal of Medicinal Plants Research. 2011;5:176-183. 